\title{
Perception of Side Effects of Chemotherapy among Cancer Patients in B.P. Koirala Memorial Cancer Hospital Bharatpur, Nepal
}

\author{
Sharmila Gurung ${ }^{1}$, Radha Acharya Pandey ${ }^{2}$ \\ 1Teaching Assistant, Pokhara Technical Health Multipurpose Institute, Simalchaur, Pokhara \\ 2 Assistant Professor, Nursing, Kathmandu University School of Medical Sciences, Dhulikhel, Kavre
}

Correspondence
Radha Acharya,
Kathmandu University,
School of Medical Sciences,
Nepal.
Email:
radhapnd@yahoo.com

DOI: http://dx.doi.org/10.3126/ jemsn.v11i4.14319

\begin{abstract}
Background \& Objectives: These side effects of chemotherapy affect the patients' daily life and quality of life adversely. It affects the different body system resulting in physical and non physical (psychosocial) side effects. Cancer patients demand information to understand chemotherapyrelated adverse effects and actions to be taken. The aim of the study is to find out the perception of side effects of chemotherapy among cancer patients. Materials and methods: A descriptive cross-sectional study was conducted among 200 cancer patients, using purposive sampling technique and data was collected via face to face interview. Descriptive as well as inferential statistics (T-test) was used to see the significant difference between dependent and independent variables. Results: The overall perceived side effects of chemotherapy include: affects work and home duties (non physical side effect), followed by anxiety, loss of appetite, affects family, affect partner, feel constantly tired (fatigue), affects social activities, feel irritable, nausea and constipation respectively. There is significant difference between perception of side effects of chemotherapy and gender of respondents. Conclusion: The perceptions of side effects of chemotherapy are different from individual to individual. Patient's perception of side effects of chemotherapy is concerned with non physical side effects rather than physical side effects.

Key words: Cancer patients, Chemotherapy, Perception, Side Effects
\end{abstract}

Citation: Gurung S, Acharya RP. Perception of Side Effects of Chemotherapy among Cancer Patients in B.P. Koirala Memorial Cancer Hospital Bharatpur, Nepal. JCMS Nepal. 2015;11(4):14-19.

\section{INTRODUCTION}

Cancer is a leading cause of death worldwide, accounting for 7.6 million deaths (around 13\% of all deaths). About $70 \%$ of all cancer deaths occurred in low and middle-income countries. Deaths from cancer worldwide are projected to continue to rise to over 13.1 million in $2030 .{ }^{1}$ According to Nepal Cancer Relief Society (NCRS) 2012 , there are 60,000 people suffering from cancer and 20,000 Nepalese people were died every year. More than $50 \%$ of people diagnosed with cancer are treated with chemotherapy. ${ }^{2}$

According to American Cancer Society, aapproximately 650,000 Americans receive chemotherapy each year. ${ }^{3}$ The annual report of BPKMCH, 2010 reveals that 2,419 cancer patients receive chemotherapy in medical oncology ward whereas 5,008 cases receive chemotherapy in day care basis. ${ }^{4}$

Despite the fact that chemotherapy increases the survival rate, it also affects the different body system adversely resulting into physical and non physical side effects. ${ }^{5}$ Almost all the cancer patients undergoing chemotherapy suffer from these side effects. Studies have shown that patients' perception of side effects of cancer chemotherapy have changed markedly. ${ }^{6}$ In the earlier studies, physical symptoms like emesis, nausea, diarrhea, hair loss, were ranked as the most troublesome side effects of chemotherapy. In the recent studies, non physical symptoms are being ranked as the most troublesome side effects of chemotherapy. ${ }^{7}$

In this study, patients ranked non physical side effect: affects my family or partner as the most troubling side effects. Loss of hair was ranked second, and constantly tired was ranked as third. Additional non physical complaints were ranked fourth, fifth and sixth: adverse effect on work or home duties, adverse effects on social activities and loss of sexual feeling, respectively. There after physical symptoms like light headedness, diarrhea, weight gain, and shortness of breath were ranked 
seventh, eighth, ninth and tenth respectively. ${ }^{6}$

Thus, these studies have shown that patients' perception of side effects of chemotherapy has shifted from physical to non physical concerns. 6 Also, studies have shown that there was a considerable difference on various issues between perceptions of patients and medical professionals. ${ }^{8}$ Thus it is essential to assess the main needs and worries of individual patients, which is an essential condition to be able to provide optimal care.

\section{MATERIALS AND METHODS}

Descriptive cross sectional research design was used in Day Care Unit of B.P. Koirala Memorial Cancer Hospital (BPKMCH), Bharatpur, Chitwan. It is one of specialized cancer hospital of Nepal. Study population consisted of all patients who have received at least one cycle of chemotherapy and above 20 years of age (study shows that cancer is common in latter age), who were present at the time of data collection.

A total of 200 cancer patients were enrolled in the studies during the period from April to May in 2012. The respondents those who were met the selection criteria in our study were purposively sampled and interviewed face to face.

A structured and semi-structured interview schedule consisting of questions related demographic information developed by reviewing literature. The content validity of the instrument was established by reviewing the literatures, seeking opinion of oncologist, related experts and doctors. We also used instrument of 5-point Likert scale $(1=$ not bothering, $2=$ a little bit bothering, $3=$ somewhat bothering, $4=$ quite a bit, $5=$ very much bothering) to summarize patient responses to the question, "How much did or would each of the following side effects of chemotherapy bother you?" It is valid scale and also used in many study too. ${ }^{5,19}$ For analysis of the data, we allocated 5 points to the most distressing (bothering) side-effect decreasing to 1 point for the side-effect ranked as the least distressing (bothering). Mean and standard deviation was calculated in each items.

The instrument was then translated into Nepali language and opinion of language expert was obtained for comprehensibility and simplicity of language and for consistency of the content. Before we started our study a written permission was obtained from the concern authorities. The study respondents were adequately informed and explained about the purposes of the study. They
Table 1: Demographic Information $(n=200)$

\begin{tabular}{|c|c|c|}
\hline Variables & Frequency & $\%$ \\
\hline \multicolumn{3}{|l|}{ Age group (in years) } \\
\hline Young adult (20-39) & 46 & 23 \\
\hline Middle adult (40-64) & 130 & 65 \\
\hline Old adult (65-100) & 24 & 12 \\
\hline \multicolumn{3}{|l|}{ Gender } \\
\hline Female & 124 & 62.0 \\
\hline Male & 76 & 38.0 \\
\hline \multicolumn{3}{|l|}{ Education level } \\
\hline Illiterate & 71 & 35.5 \\
\hline Can read and write & 44 & 22.0 \\
\hline Primary level (class 1-8) & 35 & 17.5 \\
\hline Secondary level (9-10) & 30 & 15.0 \\
\hline Higher secondary (11-12) & 9 & 4.5 \\
\hline Higher Education & 11 & 5.5 \\
\hline \multicolumn{3}{|l|}{ Ethnicity } \\
\hline Brahmin & 52 & 26.0 \\
\hline Chhetri & 18 & 9.0 \\
\hline Newar & 18 & 9.0 \\
\hline $\begin{array}{l}\text { Mangolian Group (Gurung, } \\
\text { Rai, Magar, Tamang, Pun, } \\
\text { Limbu) }\end{array}$ & 50 & 25.0 \\
\hline $\begin{array}{l}\text { Terai Group (Chaudhary, } \\
\text { Yadav, Khaton, Tharu, } \\
\text { Dev,Shah) }\end{array}$ & 47 & 25.5 \\
\hline Dalit & 15 & 7.5 \\
\hline \multicolumn{3}{|l|}{ Occupation } \\
\hline Agriculture & 76 & 38.0 \\
\hline Business & 16 & 8.0 \\
\hline Service & 36 & 18.0 \\
\hline Housewife & 66 & 33.0 \\
\hline Student & 6 & 3.0 \\
\hline \multicolumn{3}{|l|}{ Marital status } \\
\hline Unmarried & 8 & 4.0 \\
\hline Married & 170 & 85.0 \\
\hline Widow & 19 & 9.5 \\
\hline Separated & 3 & 1.5 \\
\hline
\end{tabular}

were assured of the privacy and confidentiality of the information.

Review of the patient's medical record file was done to confirm the diagnosis and number of cycle of chemotherapy. The collected data were reviewed daily for completeness and accuracy. Edited data were entered into the Statistical Package for Social Science Software (SPSS) version 16.0 for statistical analysis using descriptive and inferential statistics.

\section{RESULT}

Out of 200 respondents, more than half of the 
Table 2: Information about Diagnosis and No. of cycles of Chemotherapy

\begin{tabular}{|lll} 
Characteristics / Information & Frequency & $(\%)$ \\
Diagnosis & & \\
Gynecological cancer & 39 & 19.5 \\
\hline Gastrointestinal cancer & 48 & 24.0 \\
\hline Breast cancer & 35 & 17.5 \\
\hline Head and neck cancer & 12 & 6.0 \\
\hline Lungs cancer & 33 & 16.5 \\
\hline Blood cancer & 27 & 13.5 \\
\hline $\begin{array}{l}\text { Others (sarcoma, ca urinary } \\
\text { bladder, ca bone) }\end{array}$ & 6 & 3.0 \\
\hline No. of cycle of chemotherapy & & \\
\hline Second & 54 & 27.0 \\
\hline Third & 41 & 20.5 \\
\hline Fourth & 25 & 12.5 \\
\hline Fifth & 30 & 15.0 \\
\hline Sixth & 22 & 11.0 \\
\hline Seventh & 7 & 3.5 \\
\hline Eighth & 8 & 4.0 \\
\hline Ninth & 3 & 1.5 \\
\hline Tenth and above tenth & 10 & 5.0 \\
\hline
\end{tabular}

Table 3: Perceived Side Effects of Chemotherapy of Respondents (Min 0, Max 5)

\begin{tabular}{|ll}
\hline Physical Side Effects & $\begin{array}{l}\text { Mean Perception } \\
\text { Rating }\end{array}$ \\
\hline Nausea & $2.52 \pm 1.78$ \\
\hline Vomiting & $1.71 \pm 1.88$ \\
\hline Diarrhea & $1.60 \pm 1.91$ \\
\hline Constipation & $2.2 \pm 1.89$ \\
\hline Numbness in limbs & $2.09 \pm 1.76$ \\
\hline Hair loss & $2.06 \pm 1.67$ \\
\hline General aches & $1.76 \pm 1.62$ \\
\hline Difficulty in sleeping & $1.4 \pm 1.92$ \\
\hline Feel constantly tired & $3.09 \pm 1.41$ \\
\hline Loss of appetite & $3.38 \pm 1.76$ \\
\hline Stomatitis & $1.05 \pm 1.60$ \\
\hline Shortness of breath & $0.68 \pm 1.32$ \\
\hline Giddiness on standing up & $1.89 \pm 1.62$ \\
\hline Non Physical Symptoms & \\
\hline affects family & $3.36 \pm 1.37$ \\
\hline affects partner & $3.32 \pm 1.23$ \\
\hline affects social activities & $2.65 \pm 1.75$ \\
\hline affects work, home duties & $3.67 \pm 1.407$ \\
\hline feel low & $1.99 \pm 1.79$ \\
\hline feel irritable & $2.61 \pm 1.79$ \\
\hline difficulty in concentrating & $1.63 \pm 1.607$ \\
\hline feel anxious & $3.58 \pm 1.24$ \\
\hline causes infertility & $0.05 \pm 0.422$ \\
\hline loss of sexual feeling & $0.18 \pm 0.728$ \\
\hline
\end{tabular}

respondents were from age group 40-64 years $(65 \%)$ and mean age of the respondents was 49.13 years. The majority of the respondents were female $(62 \%)$. Most of the respondents were literate $(64.5 \%)$. Regarding ethnicity, $26 \%$ of the respondents were Brahmin. Most of the respondents were engaged in agriculture (38\%). Majority of the respondents were married (85\%). (Table 1$)$

Among 200 respondents, 24\% were suffering from gastrointestinal cancer. Regarding the number of cycles of chemotherapy, $27 \%$ of the respondents were on their second cycle of chemotherapy. (Table 2)

The five most troublesome physical side effects of chemotherapy were: loss of appetite $(3.38 \pm 1.76)$, feel constantly tired $(3.09 \pm 1.41)$, nausea $(2.52 \pm 1.78)$, constipation $(2.2 \pm 1.89)$ and numbness in limbs $(2.09 \pm 1.76)$ respectively.

Similarly, the five most troublesome non physical side effects were: affects work, home duties (3.67 \pm 1.407$)$, feel anxious (3.58 \pm 1.24$)$, affects family $(3.36 \pm 1.37)$, affects partner $(3.32 \pm 1.23)$ and affects social activities $(2.65 \pm 1.75)$ respectively.

Thus, the ten most troublesome side effects of chemotherapy were: affects work, home duties (3.67 \pm 1.407$)$, feel anxious $(3.58 \pm 1.24)$, loss of appetite (3.38 \pm 1.76$)$, affects family (3.36 \pm 1.37$)$, affects partner $(3.32 \pm 1.23)$, feel constantly tired $(3.09 \pm 1.41)$, affects social activities $(2.65 \pm 1.75)$, feels irritable $(2.61 \pm 1.79)$, nausea $(2.52 \pm 1.78)$ and constipation (2.2 \pm 1.89$)$ respectively. (Table 3)

The mean score of perception of female was $52.10 \pm 14.93$ and that of male was $42.72 \pm 16.05$. The difference observed in between them is significant since $p$ value is 0.000 that is less than 0.05 . (Table 4)

The mean score of perception of $<40$ years was $50.31 \pm 15.62$ and that of $\geq 40$ years was $47.99 \pm 16.11$. The mean perception score is slightly different but there is no significant difference since $\mathrm{p}$ value is more than 0.05 i.e. 0.385 . (Table 5)

The mean score of perception of literate was $47.023 \pm 16.93$ and that of illiterate was $51.29 \pm 13.81$. The mean perception score is slightly different but there is no significant difference since $\mathrm{p}$ value is more than 0.05 i.e. 0.071 . (Table 6)

The mean score of perception of employed was $47.17 \pm 15.95$ and that of unemployed was $50.95 \pm 15.88$. The mean perception score is slightly different but there is no significant difference since $\mathrm{p}$ value is more than 0.05 i.e. 0.109 . (Table 7) The mean score of perception of married was 
Table 4: Comparison of Mean Perception Score of Side Effects of Chemotherapy between genders

$\begin{array}{lllllll}\text { Variables } & \mathbf{n} & \text { Total Possible score } & \text { Mean score } & \text { Std. Deviation } & \text { t- value } & \text { p-value } \\ \text { Female } & 124 & 0-115 & 52.10 & 14.93 & 4.191 & 0.000 \\ \text { Male } & 76 & 0-115 & 42.72 & 16.05 & & \end{array}$

Table 5: Comparison of Mean Perception Score of Side Effects of Chemotherapy between age group $<40$ years and age group $\geq 40$ years

$\begin{array}{llclllll}\text { Age } & \mathbf{n} & \text { Total Possible score } & \text { Mean score } & \text { Std. Deviation } & \text { t- value } & \text { p value } \\ <40 \text { years } & 47 & 0-115 & 50.31 & 15.62 & & 0.871 & 0.385 \\ \geq 40 \text { years } & 153 & 0-115 & 47.99 & 16.11 & & \end{array}$

Table 6: Comparison of Mean Perception Score of Side Effects of Chemotherapy between educational levels

$\begin{array}{lllllll}\text { Education Level } & \mathbf{n} & \text { Total Possible score } & \text { Mean score } & \text { Std. Deviation } & \text { t-value } & \text { p-value } \\ \text { Literate } & 129 & 0-115 & 47.023 & 16.93 & & \\ \text { Illiterate } & 71 & 0-115 & 51.29 & 13.81 & & 0.071\end{array}$

Table 7: Comparison of Mean Perception Score of Side Effects of Chemotherapy between Occupational Status

\begin{tabular}{llllllll} 
Occupation & $\mathbf{n}$ & Total Possible score & Mean score & Std. Deviation & t-value & p-value \\
\hline Employed & 128 & $0-115$ & 47.17 & 15.95 & 1.61 & 0.109 \\
Unemployed & 72 & $0-115$ & 50.95 & 15.88 & & &
\end{tabular}

Table 8: Comparison of Mean Perception Score of Side Effects of Chemotherapy between Marital Status

$\begin{array}{lllllll}\text { Marital Status } & \text { n } & \text { Total Possible score } & \text { Mean score } & \text { Std. Deviation } & \text { t-value } & \text { p-value } \\ \text { Married } & 192 & 0-115 & 48.69 & 16.02 & & 0.683 \\ \text { Unmarried } & 8 & 0-115 & 44.75 & 15.809 & & 0.495\end{array}$

$48.69 \pm 16.02$ and that of unmarried was 44.75 \pm 15.809 . The mean perception score is slightly different but there is no significant difference since $\mathrm{p}$ value is more than 0.05 i.e. 0.495. (Table 8)

\section{DISCUSSION}

Socio-demographic findings of the study revealed that the majority $(65 \%)$ of the respondents were middle adults (between 40-64 years). The mean age of the respondents is 49.13 years, standard deviation was 13.86 and age range was from 21 years to 88 years. More than half of the respondents were female $(62 \%)$ and $64.5 \%$ the subjects were literate. $26 \%$ of the respondents were from Brahmin ethnic group, $38 \%$ were engaged in agriculture, $85 \%$ were married. Similarly, $24 \%$ were diagnosed with gastrointestinal cancer and $27 \%$ were receiving second cycle of chemotherapy.

The side effects of chemotherapy reported by patients along with their ranking by relative severity formed a distinctive profile. The five most troublesome physical side effects of chemotherapy were: loss of appetite, feel constantly tired, nausea, constipation and numbness in limbs. These findings are in contrast to the findings of the study done in Australia where vomiting was ranked first followed by nausea and hair loss. ${ }^{7}$ On the other hand, the findings of current study are supported by the study done in Australia where nausea, tiredness, loss of appetite was most troublesome side effects. ${ }^{9}$ Similarly, the current findings are supported by a study done in Korea according to which fatigue, appetite loss, nausea, constipation were most bothering side effects. ${ }^{10}$

In the same way, the study conducted in Turkey revealed that tiredness, loss of appetite, nausea were the most troublesome physical side effects of chemotherapy, which are similar to findings of current study. ${ }^{11}$ 
Another study conducted in Switzerland concluded abdominal pain, headache, and diarrhoea as most frequent side effects of chemotherapy that would bother the patients. These findings are in contrast with the findings of current study. ${ }^{12}$

A study revealed that the five issues ranked by patients were fear of metastases, fatigue, and consciousness of vulnerability, hair loss and nausea. Fear of metastases, consciousness of vulnerability and hair loss were in contrast with the findings of present study. ${ }^{8}$

As per the descriptive study conducted in Hong Kong using 10 point, $10 \mathrm{~cm}$ visual analogue scale, labelled 0 and 10 at each end where $0=$ no impact at all and $10=$ most severe impact, the most perceived physical side effects of chemotherapy were nausea, anorexia, insomnia. These are similar to the findings of current study. ${ }^{13}$

A descriptive study done in USA supported the findings of the current study as the findings were nausea, loss of hair, constantly tired, vomiting, and changes in the way things taste which were similar to the present findings except change in taste. ${ }^{14}$

A study done in Australia concluded that mouth or throat problem, infection, hair loss, fatigue, nausea and vomiting were the most bothering side effects of chemotherapy. These findings are similar to findings of current study except mouth or throat problem and infection. ${ }^{15}$

In this study, the five most troublesome non physical side effects were: affects work, home duties, feel anxious, affects family, affects partner and affects social activities. A study done in Australia supports the findings of current study as the study revealed anxiety, effect on family, effect on social lives as most bothering non physical side effects of chemotherapy. ${ }^{10}$ Similarly a study done in France also supports the findings of current study by stating that effect on family, effect on partner, effect on home and work, effect on social responsibilities as most bothering side effects of chemotherapy. ${ }^{6}$

In contrast to current study, a study conducted in Hong Kong stated that anger and depression were the most perceived non physical side effects of chemotherapy. ${ }^{13}$

A study done in Turkey showed that effect on social activities, effect on family, difficulty in concentration as most bothering non physical side effects. These are similar to the findings of current study. ${ }^{16}$

A study done in Korea and India showed that financial difficulties were the most bothering side effects of chemotherapy. This finding is similar to the current study. ${ }^{10}$

While comparing the overall perceived side effects of chemotherapy, the non physical side effect affects work and home duties was ranked as the most bothering side effect. Anxiety was ranked second, followed by loss of appetite, affects family, affect partner, feel constantly tired (fatigue), affects social activities, feel irritable, nausea and constipation respectively. These findings suggest that patients are more concern about non physical side effects. This is supported by the study done in Australia, France and USA. ${ }^{6}$

A study done in USA showed that the most troublesome side effect were fatigue, nausea and vomiting, diarrhoea, constipation, mouth sores, loss of appetite, shortness of breath. Similarly, they also mentioned effect on home, effect on work and effect on social activities as the effect of chemotherapy. ${ }^{17}$ These findings are somehow similar to the findings of current study.

Similarly, an internet survey was done in USA revealed that tiredness, nausea/vomiting, loss of appetite, depression, effect on daily activities, effect on ability to work, effect on ability to maintain relationship were the most bothering side effects of chemotherapy. These findings also support the findings of current study. ${ }^{18}$

In the current study, there is significant difference between perception and gender of the respondents. This finding was similar with the study done in Australia which shows association between perception and gender of the respondents. ${ }^{5}$

A study done in Hong Kong showed that there is significant difference between perception and occupation of respondents and also there is significant difference between perception and education level of respondents. ${ }^{13}$ These findings contrasted with the findings of current study showed no significant difference between perception and occupation and also no significant difference between perception and education level.

\section{CONCLUSION}

While comparing the perceived physical and non physical side effects of chemotherapy, the most common disturbances are work and home duties, feel anxious, loss of appetite, affect family, affects partner, feel constantly tired, affects social activities, and feels irritable, nausea and constipation. Moreover, further study of the side 
effects and beneficial effects of chemotherapy is required to achieve long term survival and to provide maximal efficacy at the cost of least toxicity for patients with cancer.

\section{Future suggestion}

It is recommended to the health care professionals to focus on conducting interventions that would address and minimize the non physical (psychosocial) aspects as patients are more concerned about these issues.

Moreover, further study of the side effects of chemotherapy used in cancer patients and their associations with certain drugs with certain side effects.

It is also recommended that the study can be done in side effects of chemotherapy that is actual physical, neurological, and psychological pharmacological effects of a given drug (such as emesis, pain, headache, bloody urine, etc), and the second is the mode of delivery of a given drug.

\section{REFERENCES}

1. World Heal Organization. Global Health Observatory (GHO), cancer mortality and morbidity; 2012.

2. Nepal Cancer Relief Society. 60,000 people suffering from cancer in Nepal. 2012 Aug 17 [cited 2015]. Available from: http://www. the himalayan times.com.

3. Littlefield J. Knit chemotherapy hats for cancer patients [Internet]. American Cancer Society. [Updated 2012; Cited 2015]. Available from: http://www.volunteer guide.org/ hours/service-projects/chemotherapy.

4. BP Koirala Memorial Cancer Hospital, Bharatpur, Nepal. Annual Report; 2010.

5. Griffin A, Butow PN, Coates AS, Childs AM, Ellis PM, Dunn SM, et al. On the receiving end. V: Patient perceptions of the side effects of cancer chemotherapy in 1993. Annals of Oncology. 1996 Feb;7(2):189-95; DOI:10.1093/oxfordjournals.annonc.a010548;

PMID:8777177.

6. Group N-SCLCC. Chemotherapy and supportive care versus supportive care alone for advanced non-small cell lung cancer (Review). The Cochrane Library. 2011:12(5):1 -31 .

7. Carelle N, Piotto E, Bellanger A, Germanaud J, Thuillier A, Khayat D. Changing patient perceptions of the side effects of cancer chemotherapy. Cancer. 2002 Jul 1;95 (1):155-63. DOI:10.1002/cncr.10630; PMID:12115329.

8. Coates A, Abraham S, Kaye SB. On the receiving end. Patient perception of the side effects of cancer chemotherapy. Eur J Cancer Clin Oncol. 1983;19:203-8. DOI:10.1016/0277-5379(83)90418-2.

9. Mulders M, Vingerhoets Ad, Breed W. The impact of cancer and chemotherapy: perceptual similarities and differences between cancer patients, nurses and physicians. Eur J Oncol Nurs. 2008;12(2):97-102. DOI:10.1016/ j.ejon.2007.10.002; PMID:18242139.

10. Kim K-S. Comfort and Quality of Life of Cancer Patients. Asian Nursing Research. 2007;1:125-35. DOI:10.1016/ S1976-1317(08)60015-8.

11. Akin S, Durna Z. A comparative descriptive study examining the perceptions of cancer patients, family caregivers, and nurses on patient symptom severity in Turkey. European Journal of Oncology Nursing. 2013 Feb;17(1):30-7. PMID:22459259.

12. Bernhard J, Maibach R, Thürlimann B, Sessa C, Aapro MS. Patients' Estimation of Overall Treatment Burden: Why Not Ask the Obvious? Journal of Clinical Oncology. 2002;20:65-72. PMID:11773155.

DOI:10.1200/JCO.20.1.65;

13. Camila S-yL. The quality of life of cancer patients receiving chemotherapy. Psychosocial Oncolgy and Palliative care in Hong Kong. 1997;55-74.

14. Lindley C, McCune JS, Thomason TE, Lauder D, Sauls A, Adkins S, et al. Perception of chemotherapy side effects cancer versus non-cancer patients. Cancer Practice Journal. 1999;7(2):59-65. DOI:10.1046/j.1523-5394.1999.07205.x.

15. Aranda S, Jefford M, Yates P, Gough K, Seymour J, Francis P. Impact of a novel nurse-led prechemotherapy education intervention (ChemoEd) on patient distress, symptom burden, and treatment related information and support needs: results from a randomised, controlled trial. Annals of Oncology. 2011;23(1)222-31. DOI:10.1093/ annonc/mdr042; PMID:21471562.

16. Iop A, Bonura S. Fatigue in cancer patients receiving chemotherapy: an analysis of published studies. Annals of Oncology. 2003;15:712-20. DOI:10.1093/annonc/mdh102.

17. Nirenberg A, Jakel P. Patients' perceptions of chemotherapy side effects burden. Paper presented at: 29th Annual Oncology Nursing Society Congress; 2004; Anaheim, California, USA: Oncology Nursing Society; 2011 Oct 27. Available from: http:// hdl.handle.net/10755/165475.

18. Hershman D CE, Malin K. Patients' Perceptions of Physician-Patient Discussions and Adverse Events with Cancer Therapy. Archives of Drug Information. 2008;1 (2):70-8. DOI:10.1111/j.1753-5174.2008.00011.x; PMID:19639029; PMCID:PMC2710992.

19. Boer-Dennert M de, Wit R de, Schmitz PIM, Djontono J, Beurden V, et al. Patient perceptions of the side-effects of chemotherapy: the influence of 5HT3 antagonists British Joumal of Cancer. 1997;76(8):1055-61. 